\title{
Impact of Talent Management on Organizational Performance: The Moderating Role of an Effective Performance Management System
}

\author{
Ahmad Ali Almohtaseb ${ }^{1}$, Hisham A Kareem Shaheen ${ }^{2}$, Khalid Mohummed Alomari ${ }^{1}$ \& Mohmmad Adnan Yousef \\ Almahameed $^{1}$ \\ ${ }^{1}$ Business Department, Al Hussein University, Ma'an, Jordan \\ ${ }^{2}$ Business School, Amman Training College, UNRWA, Amman, Jordan \\ Correspondence: Ahmad Ali Almohtaseb, Business Department, Al Hussein University, Ma'an, Jordan. E-mail: \\ Muhtaseb_ma@yahoo.com
}

Received: February 3, 2020

doi:10.5539/ijbm.v15n4p11
Accepted: March 2, 2020

Online Published: March 7, 2020

URL: https://doi.org/10.5539/ijbm.v15n4p11

\begin{abstract}
Despite the theoretical and empirical evidence that talent management improves organizational performance it is still one of the main challenges facing organizations worldwide and specifically in the health sector. This study examines the moderating effect of an effective performance management system on the relationship between talent management and organizational performance. This study was carried out on the public health sector and was specifically focused on public health workers in Jordan. The study focused on 30 public hospitals in Jordan. A survey of 430 respondents that were made up of public health workers was used for the analysis. SEM in AMOS statistical analysis package was used is this study. The findings showed that a performance management system moderates the relationship between talent management and organizational performance. This suggests that performance management system can be used as a strategy to identify talented employees; integrate, re-strategize and strengthen management-employee relationship to improve their organizational performance.
\end{abstract}

Keywords: talent management, performance management system, organizational performance, employees, health workers

\section{Introduction}

Talent management is one of the main challenges facing organizations on a global scale. It is especially challenging in the current volatile and dynamic business environment (Meyers \& van Woerkom, 2014). The reason for this is that talent management requires both quantitative and qualitative skills (Al Ariss et al., 2014; Meyers et al., 2013). Talent management encompasses putting the right employee in the right position (Devine, 2008). When employees are put in the right positions in the organizations their talent is maximized for optimum organizational success. Talent management is a relatively new area for private and public institutions and organizations. Talent management is now being prioritized by most organizations to recruit staff because it has been shown to have good results in attracting, retaining and developing employees (Baheshtiffar \& Nekoie-Moghadam, 2011). Talent management includes procedures to attract, retain and develop personnel (D'Annunzio-Green, 2008). Further, talent management is essential to an organization because of its role in helping organizations effectively entice and retain talented employees. Furthermore, the identification and the development of talent help organizations in identifying employees that can serve as leaders in the future. This dimension of talent management stresses the development of talent pools that possess a high level of leadership capability (Baheshtifar \& Nekoie-Moghadam, 2011).

In addition, talent management is also a strategy that is used to support the competence of the organization through performance enhancement, succession planning, carry development and employee development (Iles,2007). The process of managing talent is an issue facing all organizations worldwide (Gardner, 2002) the scarcity of talent is a universal concern which has led to many organizations in the world to compete for the same talent pool thus this issue viewed as a global labour market competition for talent. The global integration trend demonstrates the standardizations of organizations in recruiting, developing and managing of talent to maintain their competitive advantage and position. Hence, organizations need to adapt to global talent management best practices as well as adapting to local labor markets and requirements (Stahl et al., 2007). Previous research showed that talent management can increase organizational performance. There are some other 
factors that can affect the relationship between talent management and organizational performance. The aim of these other factors is also to improve employees' talent and organizational performance. One of these factors is performance management system (PMS) which serves as a process that ensures that employees are working hard towards accomplishing the mission and objectives of the organization (Cardy, 2004; Gruman \& Saks, 2011) referred to as the "Achilles Heel" of managing human capital (Buchner, 2007; Pulakos, 2009; Gruman \& Saks, 2011). PMS also motivates performance, enhances development of individual skills, builds performance culture, determines employee promotion, eliminates employee poor performance, and assists in implementing business strategies (Lawler, 2003; Zhang, 2012). This study argues that employment practice is undergoing major challenges that involve attracting, motivating and retaining talented employees in addition to a shortage of talent which has led to fierce competition for talent. As a result, an effective PMS is needed in any organization to enhance and strengthen the relationship between managing talented employees and the performance of the organization. Thus, this study examines the effect of PMS on the relationship between talent management and organizational performance in the health care sector.

Talent management in the health sector is more complicated than other sectors is because of the following reasons: the level of demand for talent, shortages of talent across a wide range of health care sector professions, the geographical movement of health experts, the diversity of the governance structure of health care service providers, and negative external factors are all highly challenging issues in health sector which talent management needs to solve. In addition, the inequalities that occur between the balance of demand and supply of talented workers around the world require the understanding of 'spatial distribution, regulation and global circulation' (Connell \& Walton-Roberts, 2016, p. 158) in the health care sector more than in other sectors. Further, there are issue of morality and ethics in recruitment caused by huge migration of health care specialists and the additional 'international recruitment industry to facilitate the passage of health care workers from source to destination countries' (Shaffer et al., 2016). Furthermore, there are issues of public enquiry on the quality of the output of health workers at both managerial and clinical level. These reasons are a cause for concern and it is imperative to focus on talent management in the health care sector to proffer an empirical solution to the underlying talent problems.

A example of the issues facing talent management is the Jordanian health care system. This sector undergoing numerous changes which includes the scarcity of employees as a result of job dissatisfaction and the increased pressure on employees to provide a very high-quality health care (Alawneh et al., 2015). Employees' job dissatisfaction has become a key concern to the public health care system because it has led to low quality of health care and high turnover rates in Jordanian public hospitals (Mrayyan, 2005). These challenges have serious implication on Jordanian health care sector because replacing licensed and experienced health professionals consumes time and is costly for the sector (Abdelhafiz et al., 2015; AbuAlRub\& Nasrallah, 2017; Alhamwan et al., 2015; Alawneh et al., 2015; Higazee et al., 2016). An empirical study was carried out by Hayajneh et al. (2009) in the context of Jordanian healthcare sector to ascertain the rate of turnover among registered Jordanian nurses in Jordanian hospitals. This study used a proportional random sample of $25 \%$ of the total number of hospitals in Jordan. The findings showed that the total rate of turnover is $36.6 \%$ as a result of job dissatisfaction. This finding is regarded a critical issue in Jordanian hospitals. Jordanian hospitals need further studies to identify the causes and proffer effective and efficient strategies to solve it. In a report by the Committee Secretary of Jordanian Medical Association, Dr. Walid Salah (2014), stated that 3000 doctors in Jordan wish to work outside of Jordan as a result of job dissatisfaction and that $90 \%$ of the 3000 doctors had left their positions in the Jordan Ministry of Health to seek positions abroad (Alawneh et al., 2015). This is evidence that the Jordanian health care system lacks professional health workers and there is a need to create strategies to retain the existing talented workers and attract new ones. Thus, there is need for empirical studies to focus on how to effectively manage talent in the Jordanian health care sector which will then improve their performance.

The remainder of this research focuses on the literature review and the development of the hypotheses. The research then it presents the research methodology which includes the statistical model and testing procedures. The report of the empirical results is given with a discussion on the findings. The final part of the paper is the conclusion which includes the implications, limitations and suggestions for future studies.

\section{Literature Review and Hypotheses Development}

\subsection{Talent Management and Organizational Performance}

In summary to the various discussions on talent management, it can be concluded that talent management is a multi-faceted concept that has been championed by human resource practitioners while fueled by the competition for talent and built on the foundations of strategic human resource Management (Hughes \& Rog, 
2008). In addition, it can also be deduced that talent management is imperative for at least two main purposes which are (i) that effective managing of talent ensures that organizations can efficaciously obtain and hold on to important talents, and (ii) retaining these talents for long time (Al Ariss et al., 2014).

There have been a few studies that examined the relationship between talent management and organization performance. These studies have shown a positive relationship. Kehinde (2012) examined the effect of talent management on the organizational performance. Kehinde examined sixteen firms in Nigeria and his findings showed that there is a positive relationship between talent management and the organizational performance of Nigerian firms. Kehinde recommended that firms with special talent should engage in a talent management scheme that should be totally different from their usual style of HRM. The study of Payambarpour and Hooi (2015) used a sample of 498 employees working in multinational corporations to investigate the talent management effect on organizational performance. This study used PLS-SEM application in testing the hypotheses of the study. Their findings showed that management development and strategic human resource inputs which serve as proxies for talent management are positively related with organizational performance. The authors suggested that to improve organizational performance, management development and strategic HR inputs must be considered and improved.

Nafei (2016) examined the impact of talent management on organizational performance of Egyptian firms using 370 samples of employees in industrial firms. The findings showed that there is a relationship between talent management dimensions and organizational performance. Nafei suggested that industrial firms in Egypt should improve their organizational performance by improving the dimensions of talent management. Sareen and Mishra (2016) used a sample of 206 professionals in Indian information technology (IT) firms to evaluate the impact of talent management on organizational performance. The results indicated that talent management partially affected organizational performance. The authors suggested that the effective management of the IT professionals will improve organizational growth and profitability. Najm and Manasrah (2017) used a sample of 183 bank employees of six Jordanian banks to examine the talent management and organizational performance relationship. Their findings implied that talent management dimensions have a positive effect on organizational performance. The authors suggested that there is need for organizations to develop indicators that will assist in assessing the progress of talented employees at different stages of their careers, in order to improve organizational performance. El-Dahshan et al. (2018) investigated the effect of talent management on organizational performance by focusing on 273 nurses that were randomly selected in two large hospitals in Egypt. The findings of this study showed a high positive significant relationship between organization performance and talent management components used for their study. They recommended that there is need for healthcare organizations to adopt talent management strategy so as to stay competitive in the contemporary health care domain. Based on the findings of these past studies, this study hypothesized that talent management has relationship with organizational performance in the following:

H1: There is significant impact of Talent Management on Organizational Performance

H1a: Talent Management Planning has a significant impact on organizational performance.

H1b: Compensation and Rewards have a significant impact on organizational performance.

H1c: Recruiting and Attracting have a significant impact on organizational performance.

H1d: Employee Empowerment has a significant impact on organizational performance.

H1e: Employee Engagement has a significant impact on organizational performance.

H1f: Training and planning have a significant impact on organizational performance.

H1g: Organizational Culture has a significant impact on organizational performance.

\subsection{Talent Management, Performance Management System and Organizational Performance}

Performance appraisal is moving away from a single method of the management of performance to a more integrated fragment of the overall Performance Management system. PMS has been defined as 'an integrated set of planning and review procedures which cascade down through the organization to provide a link between each individual and the overall strategy of the organization' (Smith \& Goddard 2002, p. 248). According to Armstrong (2006), PMS is a set of interrelated activities and processes that are treated holistically as integrated and key components of the organization's approach to managing performance of employees through developing the skills and capabilities of its human capital, in order to enhance organizational capability and the achievement of a sustained competitive advantage.

A performance management system, according to Vitez (2012), takes the subjectivity out of individual employee 
reviews and performance rewards that are conducted by managers. Performance management systems also create a broad sense of equality where any employee can achieve the performance rewards by following the expectations and goals identified by the company. An effective performance management system should serve as the corner stone and driving force behind all organizational decisions, work efforts and resource allocation (Costello, 1994). Grobler et al. (2002) believes that an effective performance management system is owned by line managers and driven from the top of the organization. The whole process is transparent and can be openly challenged and defended. There should be no other management process in place that conflicts with the performance management process. The effectiveness of the performance management system is formally evaluated at least once a year and appropriate improvements are made for the next cycle.

While some studies link performance management system to business performance (e.g., Bourne et al., 2005; Davis \& Albright, 2004), some studies link it with strategy (e.g., Braam \& Nijssen, 2004). Those that link it with firm strategy argued that organizational performance increases when employees are well aligned with the organizational strategy. Using a performance management system will not automatically influence organizational performance unless it is applied correctly. A Performance management system that is used to complement corporate strategy will positively affect organizational performance, while the performance management system that is not related to corporate strategy can reduce organizational performance. Effective implementation of performance management systems assists in improving the quality of employees' work, and enhances the interaction between employees and managers. It also facilitates better understanding of organizational goals and job expectations. A Performance management system also increases psychological commitment of employees and motivates and coordinates a more dynamic work culture. Thus, based on the argument that performance management system improves organizational performance, this study examines the moderating effect of performance management system on talent management and organizational performance relationship with the following hypotheses:

$\mathrm{H} 2$ : Performance management system moderates the relationship between talent management and organizational performance

H2a: Performance management system moderates by strengthening the relationship between talent management planning and organizational performance.

$\mathrm{H} 2 \mathrm{~b}$ : Performance management system moderates by strengthening the relationship between compensation and rewards and organizational performance.

$\mathrm{H} 2 \mathrm{c}$ : Performance management system moderates by strengthening the relationship between recruiting and Attracting and organizational performance.

H2d: Performance management system moderates by strengthening the relationship between employee empowerment and organizational performance.

H2e: Performance management system moderates by strengthening the relationship between employee engagement and organizational performance.

H2f: Performance management system moderates by strengthening the relationship between training and development and organizational performance.

H2g: Performance management system moderates by strengthening the relationship between organizational culture and organizational performance.

\section{Methodology}

\subsection{Study Population and Sample}

The Health care sector in Jordan was the study population of this research. This research focused on the health care sector in Jordan for the following reasons: the scarcities of talented health workers, ethics and morality in recruitment of health professionals, quality of the output, and the levels of training and continuing education and sustenance of the professional competence of Jordanian health care workers (Abdelhafiz et al., 2015; AbuAlRub\& Nasrallah, 2017; Alhamwan et al., 2015; Alawneh et al., 2015; Higazee et al., 2016). The sample of this study incuded 30 public hospitals in Jordan with a 4,373 bed capacity that constituted $37.1 \%$ of hospitals under the Ministry of Health and constituted $28.8 \%$ of the total number of Jordanian hospitals (Alawneh et al., 2015; Ministry of Health, 2018; Saif, 2017). 600 questionnaires were distributed to health care workers in these public hospitals and 454 were retrieved. Questionnaires that had incomplete responses were not included. 430 responses were finally applied for this study, representing a $71.67 \%$ response rate. 


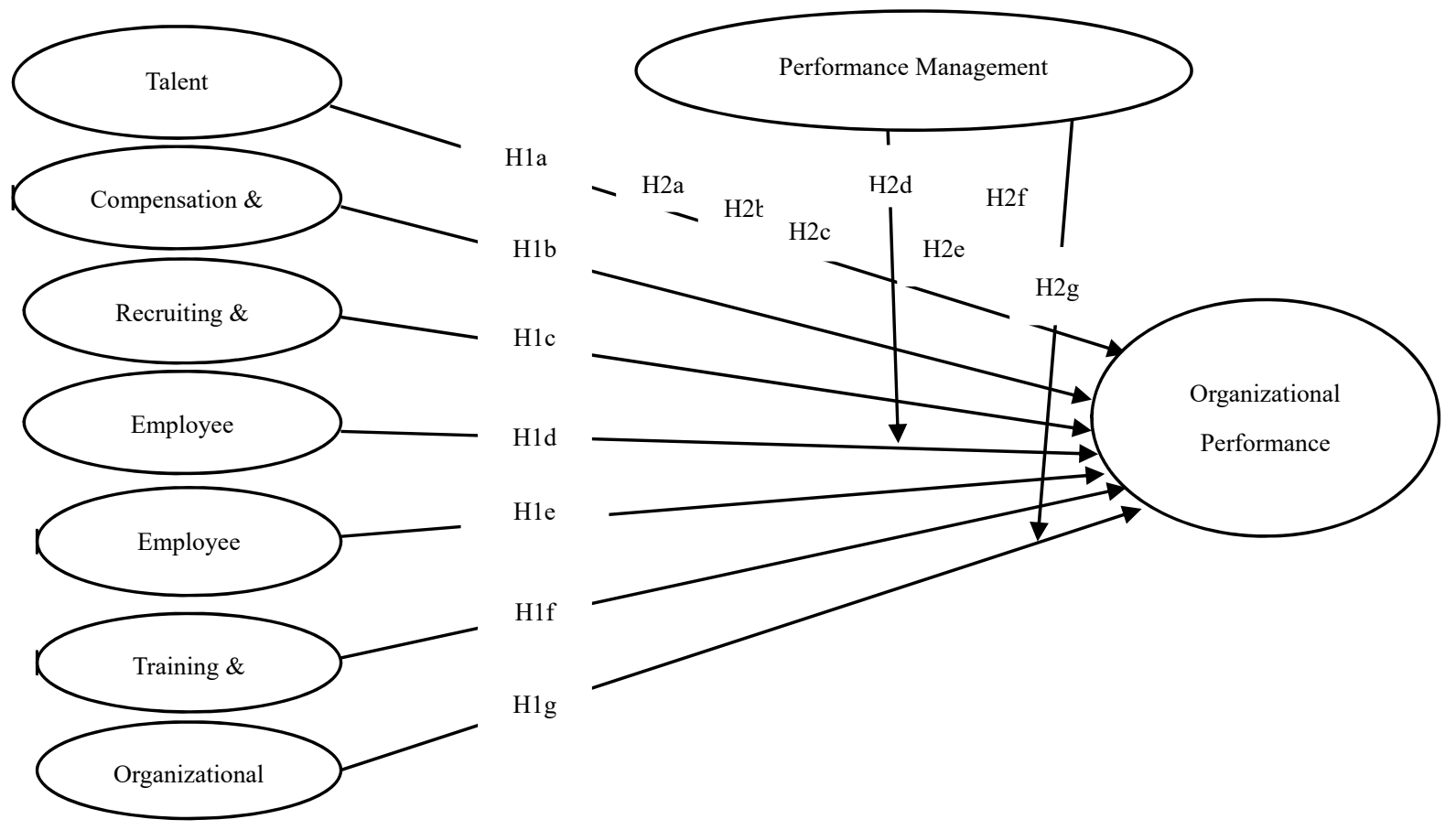

Figure 1. Proposed empirical model

\subsection{Measures}

This study explored previous research to certify both the content and face validity of the measures adapted. The constructs which are the dimensions of talent management were adapted from the study of Heinen and O'Neill (2004) and Ali (2011). Four scale items each for Talent management planning, compensation and rewards, recruiting and attracting, employee empowerment, employee engagement, and organizational culture were adapted from the study of Heinen and O'Neill (2004), while four scale items for training and development were adapted from the study of Ali (2011). This makes it a total of twenty-eight questions for talent management. The scale for performance management system (four items) was adapted from the study of Ying (2013) and Zhang (2012). Organization performance was measured using four items adapted from the study of Darroch (2003). 
Table 1. Sample characteristics

\begin{tabular}{|c|c|c|}
\hline Characteristics & Freq & Percent \\
\hline Gender & & $\%$ \\
\hline Male & 194 & 45 \\
\hline Female & 236 & 55 \\
\hline Age & & $\%$ \\
\hline $16-25$ & 242 & 56 \\
\hline $26-35$ & 106 & 25 \\
\hline $36-45$ & 64 & 15 \\
\hline Above 45 & 18 & 4 \\
\hline Education & & $\%$ \\
\hline Diploma & 210 & 49 \\
\hline Bachelor & 161 & 37 \\
\hline Master & 59 & 14 \\
\hline Experience & & $\%$ \\
\hline $0-2$ & 94 & 22 \\
\hline $3-5$ & 135 & 31 \\
\hline $6-10$ & 128 & 30 \\
\hline Above 10 & 73 & 17 \\
\hline
\end{tabular}

Table 1 shows that the number of female respondents is higher (236) than the male respondents (194). The age of most respondents is between the ages of 16 years to 35 years. 49 percent of respondents are diploma holder compared to 37 percent and 14 percent with bachelor's and master's degree, respectively. The majority of the respondents have 3-5 years working experience as health care workers in public hospitals.

In examining the proposed model and the hypotheses, the structural equation modeling (SEM) in AMOS 24.0 version was employed by this study. The purpose of applying SEM in AMOS is because it is a sophisticated software which performs factor analysis (CFA: measurement of the model) and regression analysis (Path analysis: structural model) simultaneously.

\section{Data Analysis}

The sample set was checked for the potential issue of outliers, missing values and multi-co linearity (VIF $<10$ and Tolerance $=0-1$ ). The findings did not show any issue in the sample set.

\subsection{Descriptive Statistics, Reliability and Correlation Matrix}

Table 2. depicts the summary of the descriptive statistics, the correlation matrix, average variance extracted (AVE) and the composite reliability (CR). Talent management planning (TMP) has a significant correlation with performance management system $(\mathrm{PMS})(\mathrm{at} \mathrm{r}=.241, \mathrm{p}<.05)$ and organizational performance $(\mathrm{PER})($ at $\mathrm{r}=.374$, $\mathrm{p}<.01)$. Compensation and rewards $(\mathrm{COM})$ have a significant correlation with performance management system (PMS) (at $\mathrm{r}=.403, \mathrm{p}<.01)$ and organizational performance $(\mathrm{PER})($ at $\mathrm{r}=.295, \mathrm{p}<.05)$. Recruiting and attracting (REC) have a significant correlation with performance management system (PMS) (at $\mathrm{r}=.372, \mathrm{p}<.01)$ and organizational performance (PER) (at $\mathrm{r}=.522, \mathrm{p}<.05)$. Employee empowerment (EMP) has a significant correlation with performance management system (PMS) (at $\mathrm{r}=.348, \mathrm{p}<.05$ ) and organizational performance (PER) (at $\mathrm{r}=.235, \mathrm{p}<.05)$. Employee engagement $(\mathrm{ENG})$ had a significant correlation with performance management system (PMS) (at $\mathrm{r}=.422, \mathrm{p}<.05)$ and organizational performance $(\mathrm{PER})($ at $\mathrm{r}=.214, \mathrm{p}<.05)$. Training and development (T\&D) had a significant correlation with performance management system (PMS) (at $\mathrm{r}=.526, \mathrm{p}<.05)$ and organizational performance $(\mathrm{PER})($ at $\mathrm{r}=.381, \mathrm{p}<.05)$. Organizational culture (CUL) had a significant correlation with performance management system (PMS) (at $\mathrm{r}=.329, \mathrm{p}<.05$ ) and organizational performance (PER) (at $\mathrm{r}=.256, \mathrm{p}<.01$ ). Furthermore, performance management system (PMS) had a positive significant correlation with organizational performance (PER) (at $r=.482, p<.05)$. These results depict the acceptance of the structural relationships proposed for this study. 
Table 2. Descriptive statistics, reliability and correlation matrix

\begin{tabular}{|c|c|c|c|c|c|c|c|c|c|c|c|c|c|c|c|}
\hline \multicolumn{2}{|c|}{ Constructs } & \multirow{2}{*}{$\frac{\text { Mean }}{3.629}$} & \multirow{2}{*}{$\frac{\text { SD }}{0.625}$} & \multirow{2}{*}{$\begin{array}{l}\text { Alpha( ) } \\
0.776\end{array}$} & \multirow{2}{*}{$\begin{array}{l}\text { CR } \\
0.7884\end{array}$} & \multirow{2}{*}{$\begin{array}{l}\text { AVE } \\
0.5217\end{array}$} & \multirow{2}{*}{$\begin{array}{l}1 \\
0.714\end{array}$} & \multirow[t]{2}{*}{2} & \multirow[t]{2}{*}{3} & \multirow[t]{2}{*}{4} & \multirow[t]{2}{*}{5} & \multirow[t]{2}{*}{6} & \multirow[t]{2}{*}{7} & \multirow[t]{2}{*}{8} & \multirow[t]{2}{*}{9} \\
\hline 1 & TMP & & & & & & & & & & & & & & \\
\hline 2 & $\mathrm{COM}$ & 3.471 & 0.651 & 0.763 & 0.7922 & 0.5663 & $.373^{*}$ & 0.709 & & & & & & & \\
\hline 3 & REC & 3.544 & 0.574 & 0.792 & 0.8113 & 0.5242 & $.458^{* *}$ & $.233^{*}$ & 0.711 & & & & & & \\
\hline 4 & EMP & 3.685 & 0.637 & 0.784 & 0.7782 & 0.5055 & $.247^{* *}$ & $.573 * *$ & $.254 * *$ & 0.742 & & & & & \\
\hline 5 & ENG & 3.693 & 0.562 & 0.725 & 0.8025 & 0.5725 & $.471 * *$ & $.364 * *$ & $.431 * *$ & $.416^{*}$ & 0.731 & & & & \\
\hline 6 & $\mathrm{~T} \& \mathrm{D}$ & 3.572 & 0.611 & 0.741 & 0.7948 & 0.5251 & $.282 * *$ & $.442 * *$ & $.362 * *$ & $.424 *$ & $.275^{*}$ & 0.728 & & & \\
\hline 7 & CUL & 3.751 & 0.596 & 0.736 & 0.8146 & 0.5834 & $.502 *$ & $.325^{*}$ & $.419^{*}$ & $.293 *$ & $.517^{*}$ & $.452 *$ & 0.739 & & \\
\hline 8 & PMS & 3.684 & 0.647 & 0.801 & 0.8217 & 0.5527 & $.241 *$ & $.403 * *$ & $.372 * *$ & $.348^{*}$ & $.422 *$ & $.526^{*}$ & $.329 *$ & 0.745 & \\
\hline 9 & PER & 3.775 & 0.679 & 0.812 & 0.8210 & 0.5602 & $.374 * *$ & $.295^{*}$ & $.522 *$ & $.235^{*}$ & $.214^{*}$ & $.381 *$ & $.256^{*}$ & $.482 *$ & 0.727 \\
\hline
\end{tabular}

Notes. ${ }^{* *}$ Significant at $\mathrm{p}<.01$ and $*$ significant at $\mathrm{p}<.05$. Diagonal italics are the square root of AVE.

$\mathrm{CR}=$ Composite Reliability. AVE= Average Variance Extracted.

This study carried out a t-test to evaluate the possible non-response bias issue through comparison of the early $(n=30)$ and late $(n=30)$ respondents, which is in line with Rogelberg and Stanton (2007) guidelines. The results of the t-test showed that there is insignificant difference between the two groups (at $\mathrm{p}>.05$ ), indicating the absence of non-response bias in this study. In addition, this study also evaluated the possible common method bias (CMB) issue as stressed by Podsakoff et al. (2003). Firstly, the common latent factor (CLF) and the original measurement model in CFA were linked together, and the results showed no significant loss in factors loadings, while CFA estimates were still significant $($ at $\mathrm{p}<.05)$. Secondly, the common variance shared between observed variables and CLF were lower than 50\%, indicating that there is no concern for CMB in this study. Thirdly, CMB should exist if the values of correlation are higher than .90 . However, the results of the correlation showed that no values of correlation are higher than 0.90 in this study. Therefore, all these results demonstrate that there is absence of CMB in this study.

This study also tested the convergent validity by analyzing the values ofcomposite reliability (CR), Cronbach's alpha, average variance extracted (AVE) and factor loadings (Hair et al., 2012). The values of Cronbach's alpha that are shown in Table 2 are higher than .70 of the threshold criteria because they ranged from .75 to 80 . Meanwhile, the values of AVE and CR range from .50 to .56 and .79 to .81 , respectively, which is above the acceptable level of .50 (for AVE) and .70 (for CR), respectively. Moreover, the factor loadings are higher compared to the .60 threshold level (see Table 3). The solidity of the convergent validity of the study instrument has been proved by all these findings. In addition, in line with the method of Fornell and Larcker (1981), the discriminant validity of the research scales adapted for this study were evaluated by comparing the values of correlations and the square root of AVE. The results in Table 2 show that the correlation values are less than the square root of AVE, implying the absence of discriminant validity in this study. 
Table 3. Confirmatory factor analysis

\begin{tabular}{|c|c|c|c|}
\hline Variables & & Paths & Loadings \\
\hline & & TMP $1<-$ Talent Mgt Planning & 0.652 \\
\hline \multirow[t]{28}{*}{ Talent Management } & Talent Mgt Planning & TMP2<— Talent Mgt Planning & 0.695 \\
\hline & & TMP3<— Talent Mgt Planning & 0.724 \\
\hline & & TMP4<— Talent Mgt Planning & 0.824 \\
\hline & & COM $1<-$ Compensation \& Rewards & 0.783 \\
\hline & Compensation \& Rewards & COM $2<-$ Compensation \& Rewards & 0.753 \\
\hline & & COM $3<$ Compensation \& Rewards & 0.818 \\
\hline & & COM4 $<$ - Compensation \& Rewards & 0.682 \\
\hline & & REC1 $<$ - Recruiting \& Attracting & 0.801 \\
\hline & Recruiting \& Attracting & REC $2<$ - Recruiting \& Attracting & 0.640 \\
\hline & & REC $3<-$ Recruiting \& Attracting & 0.791 \\
\hline & & REC4 $<-$ Recruiting \& Attracting & 0.711 \\
\hline & & EMP1 <- Employee Empowerment & 0.674 \\
\hline & Employee Empowerment & EMP2 <- Employee Empowerment & 0.629 \\
\hline & & EMP3 <-Employee Empowerment & 0.734 \\
\hline & & EMP4 <- Employee Empowerment & 0.609 \\
\hline & & ENG1 <- Employee Engagement & 0.772 \\
\hline & Employee Engagement & ENG2 $<-$ Employee Engagement & 0.759 \\
\hline & & ENG3 $<-$ Employee Engagement & 0.689 \\
\hline & & ENG4 <- Employee Engagement & 0.808 \\
\hline & & T\&D $1<$ - Training \& Development & 0.722 \\
\hline & Training \& Development & T\&D2 <- Training \& Development & 0.738 \\
\hline & & T\&D3 $<$ - Training \& Development & 0.651 \\
\hline & & T\&D4 <- Training \& Development & 0.688 \\
\hline & & CUL1 $<$ - Organizational Culture & 0.744 \\
\hline & Organizational Culture & CUL2 $<$ - Organizational Culture & 0.752 \\
\hline & & CUL3 $<$ - Organizational Culture & 0.633 \\
\hline & & CUL4 $<$ - Organizational Culture & 0.671 \\
\hline & & PMS1 <- Performance Mgt System & 0.830 \\
\hline \multirow[t]{4}{*}{ Performance Mgt System } & & PMS2 <- Performance Mgt System & 0.703 \\
\hline & & PMS3 <- Performance Mgt System & 0.766 \\
\hline & & PMS4 <- Performance Mgt System & 0.719 \\
\hline & & PER $1<$ - Organizational Performance & 0.799 \\
\hline \multirow[t]{3}{*}{ Organizational Performance } & & PER $2<-$ Organizational Performance & 0.753 \\
\hline & & PER3 $<-$ Organizational Performance & 0.784 \\
\hline & & PER4 <- Organizational Performance & 0.828 \\
\hline
\end{tabular}

This study carried out the confirmatory factor analysis (CFA) in validating the proposed model, by linking the three variables (i.e., independent, dependent and moderating variables) to each other. A good fit and acceptable measurement model that attained the threshold criteria for model acceptance as stressed by Hair et al. (2012) and is confirmed from the CFA results. All the estimates of the items are at a significant (at $\mathrm{p}<.05$ ) (see Table 3). Also, as in Table 4, the indices of model fit imply the data are a good fit. 
Table 4. CFA model fitness indices

\begin{tabular}{llll}
\hline Fitness Indicators & Measurement Model & Structural Model & Threshold indices \\
\hline CMIN/DF & 3.000 & 2.561 & $<3$ \\
CFI & 0.952 & 0.977 & $<.90$ \\
SRMR & 0.052 & 0.054 & $<.06$ \\
RMSEA & 0.078 & 0.069 & $<.08$ \\
P-Value & 0.000 & 0.000 & $>.05$ \\
TLI & 0.945 & 0.978 & $>.90$ \\
NFI & 0.927 & 0.983 & $>.90$ \\
NNFI & 0.923 & 0.949 & $>.90$ \\
IFI & 0.951 & 0.978 & $>.95$ \\
GFI & 0.964 & 0.985 & $>.95$ \\
AGFI & 0.935 & 0.967 & $>.90$ \\
\hline
\end{tabular}

\subsection{Structural Model Test}

After the measurement model had been accepted, as shown in Table 4, the measurement model is then converted to the structural model which is also a good fit and accomplished the model fitness threshold indices (Hair et al., 2012). After this, the standardized path coefficients of the structural model were computed (as shown in Table 5). It shows that talent management planning (at $\beta=.241, p=.000$ ), compensation and rewards (at $\beta=.435, p=.000$ ), recruiting and attracting (at $\beta=.393, p=.001$ ), employee empowerment(at $\beta=.227, p=.003$ ), employee engagement (at $\beta=.350, p=.020)$, training and development (at $\beta=.514, p=.034)$, and organizational culture $($ at $\beta=.230, p=.000)$ have significant impact on organizational performance. Thus, H1a, H1b, H1c, H1d, H1e, H1f and H1g are accepted. Table 5 also shows the results of the moderating effect in AMOS, where there is a 95 percent confidence interval of the moderating effect of performance management system. Performance management system (at $\beta=.163, p=.004$ ) moderates the relationship between talent management planning and organizational performance. Performance management system (at $\beta=.226, p=.014$ ) moderates the relationship between compensation and rewards and organizational performance. Performance management system $($ at $\beta=.182, p=.023)$ moderates the relationship between recruiting and attracting and organizational performance. Performance management system (at $\beta=.143, p=.002$ ) moderates the relationship between employee empowerment and organizational performance. Performance management system (at $\beta=.215, p=.041$ ) moderates the relationship between employee engagement and organizational performance. Performance management system (at $\beta=.282$, $\mathrm{p}=.024)$ moderates the relationship between training and development and organizational performance. Performance management system (at $\beta=.109, \mathrm{p}=.002$ ) moderates the relationship between organizational culture and organizational performance.

Table 5. The findings of hypotheses testing

\begin{tabular}{|c|c|c|c|c|c|}
\hline Paths & Estimate & S.E & C.R (t) & p-value & Decision \\
\hline H1a: TMP $\rightarrow$ PER & 0.241 & 0.032 & 4.471 & 0.272 & Rejected \\
\hline H1b: COM $\rightarrow$ PER & 0.435 & 0.069 & 1.868 & 0.000 & Accepted \\
\hline H1c: $\mathrm{REC} \rightarrow$ PER & 0.393 & 0.057 & 6.524 & 0.557 & Rejected \\
\hline H1d: $\mathrm{EMP} \rightarrow$ PER & 0.227 & 0.044 & 5.403 & 0.431 & Rejected \\
\hline H1e: $\mathrm{ENG} \rightarrow$ PER & 0.350 & 0.048 & 6.439 & 0.020 & Rejected \\
\hline H1f: $\mathrm{T} \& \mathrm{D} \rightarrow \mathrm{PER}$ & 0.514 & 0.023 & 2.382 & 0.034 & Accepted \\
\hline \multirow[t]{2}{*}{ H1g: CUL $\rightarrow$ PER } & 0.230 & 0.018 & 3.647 & 0.000 & Accepted \\
\hline & Moderating Effect & S.E & LB 95\% CI & UB95\% CI P-Value & \\
\hline $\mathrm{H} 2 \mathrm{a}: \mathrm{TMP} \leftarrow \mathrm{PMS} \rightarrow \mathrm{PER}$ & 0.163 & 0.041 & 0.115 & 0.135 .004 & Accepted \\
\hline $\mathrm{H} 2 \mathrm{~b}: \mathrm{COM} \leftarrow \mathrm{PMS} \rightarrow \mathrm{PER}$ & 0.226 & 0.036 & 0.027 & 0.034 .0140 & Accepted \\
\hline $\mathrm{H} 2 \mathrm{c}: \mathrm{REC} \leftarrow \mathrm{PMS} \rightarrow \mathrm{PER}$ & 0.182 & 0.024 & 0.142 & 0.146 .0232 & Accepted \\
\hline $\mathrm{H} 2 \mathrm{~d}: \mathrm{EMP} \leftarrow \mathrm{PMS} \rightarrow \mathrm{PER}$ & 0.143 & 0.022 & 0.134 & 0.285 .002 & Accepted \\
\hline $\mathrm{H} 2 \mathrm{e}: \mathrm{ENG} \leftarrow \mathrm{PMS} \rightarrow \mathrm{PER}$ & 0.215 & 0.017 & 0.004 & 0.051 .0411 & Accepted \\
\hline 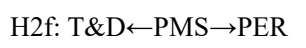 & 0.282 & 0.011 & 0.182 & 0.025 .0242 & Accepted \\
\hline $\mathrm{H} 2 \mathrm{~g}: \mathrm{CUL} \leftarrow \mathrm{PMS} \rightarrow \mathrm{PER}$ & 0.109 & 0.029 & 0.125 & 0.113 .002 & Accepted \\
\hline
\end{tabular}

Notes. $\mathrm{TMP}=$ Talent Management Planning, $\mathrm{COM}=$ Compensation and Rewards, $\mathrm{REC}=$ Recruiting and Attracting, EMP $=\mathrm{Employee}$ Empowerment, $\mathrm{ENG}=$ Employee Engagement, $\mathrm{T} \& \mathrm{D}=$ Training and Development, $\mathrm{CUL}=$ Organizational Culture, $\mathrm{PMS}=\mathrm{Performance}$ Management System, PER= Organizational Performance. 


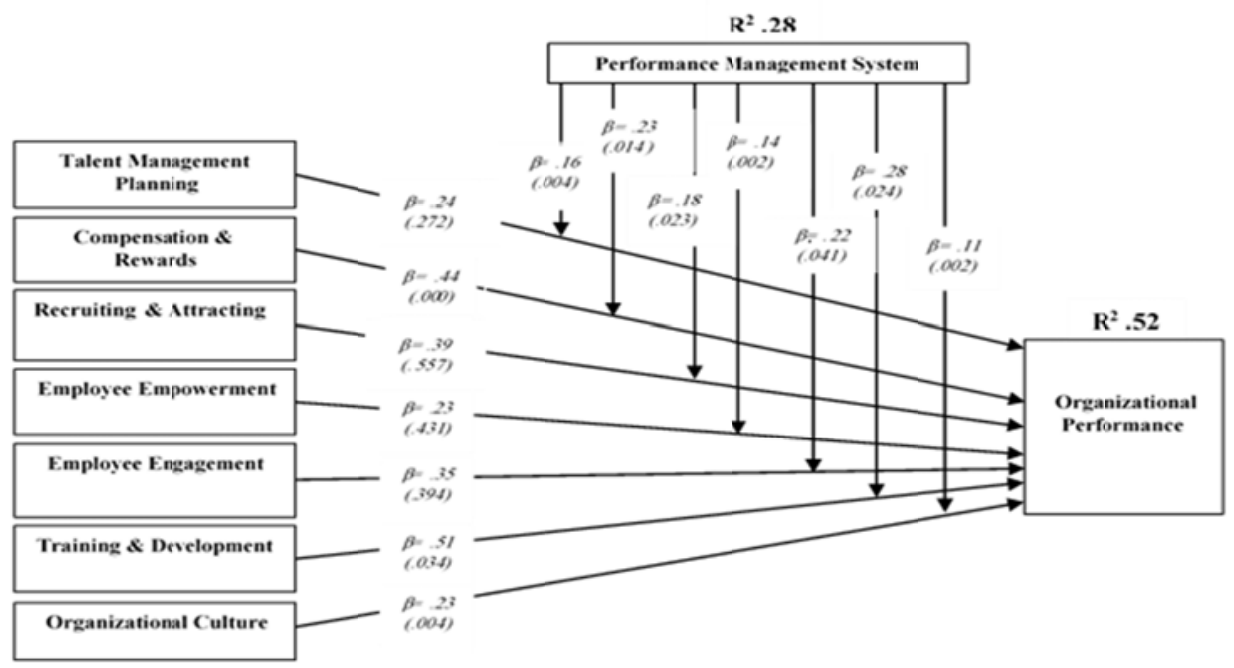

Figure 2. Path diagram

The values of the model prediction accuracy (R squares) is depicted in Figure 2. The R-square of .52 indicates that the dimensions of talent management (i.e., talent management planning, compensation and rewards, recruiting and attracting, employee empowerment, employee engagement, training and development, and organizational culture) explained the $52 \%$ difference in organizational performance. However, with the interaction of performance management system as a moderating effect, the R-square of .28 which indicates that the dimension of talent management (i.e., talent management planning, compensation and rewards, recruiting and attracting, employee empowerment, employee engagement, training and development, and organizational culture) explained the $28 \%$ difference in organizational performance. These findings therefore showed that the proposed structural relationships of this study had been explained.

\subsection{Discussion}

This research examined the moderating effect of performance management systems on the impact of talent management on organizational performance. The test was carried out through the dimensions of talent management which were used as sub-hypotheses to interpret the study. Hypothesis H1a assumed that talent management planning had a significant impact on organizational performance and the findings rejected the assumption. The plausible reason for the outcome is that the management of Jordanian public health workers refused to optimize the capitalization of talented health workers which they should have used as a strategy to attract, motivate and retain talented staff that could improve their organizational performance (Gakovic\& Yardley,2007; Stevens, 2008). Hypothesis H1b assumed that compensation and rewards have a significant effect on organizational performance and the findings supported the assumption. The probable reason for this outcome is that the management of public health workers in Jordan involves compensating and rewarding health workers through incentives and bonus schemes which help in keeping and creating some talented health workers and improve their organizational performance (Berger \& Berger, 2003; Richman et al., 2008).

Furthermore, hypothesis H1c assumed that recruiting and attracting employees had a significant influence on organizational performance and the findings rejected the assumption. The possible reasons for these outcomes are that the management of Jordanian health workers does not have an effective recruiting system that will enable them recruit and attract qualified candidates that could improve their organizational performance. Hypothesis H1d assumed that employee empowerment had a significant impact on organizational performance and the findings rejected the assumption. The plausible reason is that the management of Jordanian public health workers does not provide enough commitment to empower the health workers and also there is no effective delegation of authority from the top managers to other staff (DuBrin, 2010; Gomez-Mejiaet al., 2004).

In addition, hypothesis H1e assumed that employee engagement has a significant effect on organizational performance and the findings rejected the assumption. The probable reason for this outcome is that the health workers in Jordanian public health does not engage and have sense of belonging in working in the Jordanian public health setting. These health care workers do not have the emotional and intellectual connection that workers need for their job to influence organizational performance (Kennedy \&Daim 2010; Richmanet al., 2008). 
Hypothesis H1f assumed that training and development have a significant impact on organizational performance and the findings supported the assumption. The plausible reason is for this result that Jordanian health care workers engaged in some training and development that improved their talent and resulted in enhancing their organizational performance (DuBrin, 2010; Gomez-Mejia et al., 2004). Hypothesis H1g assumed that organizational culture has a significant influence on organizational performance and the findings supported the assumption. The possible reason for this result is that the public health workplace culture has a positive influence on the talent of the workers which then improves organizational performance (Ahlrichs, 2003; Phillips \& Connell, 2003). Therefore, the findings of the significant impact of talent management on organizational performance is consistent with past studies (e.g., Collings \& Mellahi, 2009; El Dahshan et al., 2018;Kehinde, 2012; Milky, 2013;Nafei, 2016;Najm\&Manasrah, 2017; Sadri et al., 2015; Sareen \& Mishra, 2016).

The second set of hypotheses (H2a, H2b, H2c, H2d, H2e, H2f and H2g) was used to test the moderating effect of performance management system on the relationship between the dimensions of talent management and organizational performance. The findings indicate that performance management system moderates by strengthening the relationship between the dimensions of talent management and organizational performance. This implies that performance management system integrates the management of organization and employees' performance which then strengthened the talent of the Jordanian public health workers since the individual level performance is in line with the organizational level performance (Vaiman \& Vance, 2008).

\section{Conclusions}

The aim of this study was to examine the moderating effect of performance management system on the relationship between talent management and organizational performance. This study was carried out on public health sector and specifically focused on public health workers in Jordan. The study sample was made up of 30 public hospitals and survey of 430 respondents from the public workers was used for the analysis. The study used SEM in AMOS 24.0 and the findings showed that performance management system moderates the relationship between talent management and organizational performance. This suggests that the management of Jordanian public hospitals should use a performance management system as a tool to integrate, re-strategize and strengthened their relationship with the health workers to improve their organizational performance. As an effective performance management system helps management to measure, deliver and reward employee performance, it also assists in in dentifying talented employees that can be retained to improve organizational performance. This study contributes to existing studies on the importance, usefulness and impact of talent management and performance management system on organizational performance. This study is consistent with past studies (e.g., Nafei, 2016; Mathias \& Jackson, 2006; Vaiman\& Vance, 2008) that argued that performance management system is a system that positively improves talent management and strengthen organizational performance through integrating and reconfiguring management strategies.

The implications of this study is that the a weak talent management strategy practiced by management of Jordanian public health sector has led to the issue of shortages of talented health workers and huge migration of health workers from the Jordanian public health settings (Abdelhafiz et al., 2015; AbuAlRub \& Nasrallah, 2017; Alhamwan et al., 2015; Alawneh et al., 2015; Higazee et al., 2016) can be reconfigured with an effective performance management system that will measure, deliver and reward employee performance and identify talented health workers that can be retained to strengthen and improve Jordanian public health performance. The application of an effective performance management system in the public health system to strengthen the effort of identifying talented health workers may serve as a response that is quantitative (i.e., by giving room to enough health workers) and qualitative (i.e., by providing health worker with the right level of skills). In addition, the use of performance management system to strengthen the relationship between talent management and organizational performance is applicable to all environments worldwide, especially in a volatile and dynamic environment where talent management has become one of the main issues facing organizations (Meyers \& van Woerkom, 2014).

As talent management has been a challenge facing many organizations globally, there is need for empirical studies to test the implications of performance management system on the relationship between talent management and organizational performance in other specifically in other dynamic and volatile economies. Thus, future studies can examine the influence of performance management on the talent management organizational and performance relationship by focusing on other sectors and contexts. 


\section{References}

Abdelhafiz, I. M., Alloubani, A. M., \& Almatari, M. (2016). Impact of leadership styles adopted by head nurses on job satisfaction: a comparative study between governmental and private hospitals in Jordan. Journal of Nursing Management, 24, 384-392. https://doi.org/10.1111/jonm.12333

AbuAlRub, R. F., \& Nasrallah, M. A. (2017). Leadership behaviours, organizational culture and intention to stay amongst Jordanian nurses. International Nursing Review. https://doi.org/10.1111/inr.12368

Ahlrichs, N. (2003). Manager of Choice: Five Competencies for Cultivating Top Talent, California: Davies-Black.

Al Ariss, A., Cascio, W. F., \& Paauwe, J. (2014). Talent management: Current theories and future research directions. Journal of World Business, 49(2), 173-179. https://doi.org/10.1016/j.jwb.2013.11.001

Alawneh, S. M. A., Ahmad, A. A., \& Siron, R. (2015). The Mediating Effect of Employees' Job Satisfaction between Leadership Styles and Patients Satisfaction in the Jordanian Public Hospitals. International Review of Management and Business Research, 4(3).

Alhamwan, M., Mat, N., \& AlMuala, I. (2015). The Impact of Organizational Factors on Nurses Turnover IntentionBehavior at Public Hospitals in Jordan: How Does Leadership, Career Advancement and Pay-Level Influence the Turnover Intention Behavior among Nurses. Journal of Management and Sustainability, 5(2). https://doi.org/10.5539/jms.v5n2p154

Ali, A. (2011). Talent management in the Middle East. In H. Scullion, and D.G. Collings, (Eds.), Global TalentManagement (pp. 155-177). New York: Routledge.

Armstrong, M. (2006). Performance Management: Key Strategies and Practical Guidelines. Kogan Page.

Beheshtifar, M., \& Nekoie-Moghadam, M. (2011). Talent Management: A Complementary Process for Succession Planning. Life Science Journal, 8(4), 474-478.

Berger, L., \& Berger, D. (2003). The Talent Management Handbook Creating Organizational Excellence by Identifying, Developing and Promoting Your Best People. USA: McGraw-Hill.

Bourne, M., Kennerley, M., \& Franco-Santos, M. (2005). Managing trough measures: A study of impact on performance. Journal of Manufacturing Technology Management, 16(4), 373-395. https://doi.org/10.1108/17410380510594480

Braam, G. J., \& Nijssen, E. J. (2004). Performance effects of using the balanced scorecard: A note on the Dutch experience. Long range planning, 37(4), 335-349. https://doi.org/10.1016/j.lrp.2004.04.007

Buchner, T. W. (2007). Performance management theory: A look from the performer's perspective with implications for HRD. Human Resource Development International, 10, 59-73. https://doi.org/10.1080/13678860601170294

Cardy, R. L. (2004). Performance management: Concepts, skills, and exercises. Armonk, NY: M. E. Sharpe.

Collings, D. G., \& Mellahi, K. (2009). Strategic Talent Management: A review and research agenda. Human Resource Management Review, 19(4), 304-313. https://doi.org/10.1016/j.hrmr.2009.04.001

Connell, J., \& Walton-Roberts, M. (2016). What about the workers? The missing geographies of health care. Progress in Human Geography, 40(2), 158-176. https://doi.org/10.1177/0309132515570513

Costello, S. J. (1994). Effective performance management. Burr Ridge, IL: Business One/Irwin/Mirror Press.

D'Annunzio-Green, N. (2008). Managing the Talent Management Pipeline. International Journal of Contemporary Hospitality Management, 20(7), 807. https://doi.org/10.1108/09596110810897628

Darroch, J. (2003). Developing a Measure of Knowledge Management Behaviors and Practices. Journal ofKnowledge Management, 7(5), 41-54. https://doi.org/10.1108/13673270310505377

Davis, S., \& Albright, T. (2004). An investigation of the effect of Balanced Scorecard implementation on financial performance. Management Accounting Research, 15(2), 135-153. https://doi.org/10.1016/j.mar.2003.11.001

Devine, M. P. (2008). Talent Management in Public Sector. A shridge business School. Retrieved on 22nd May 2013 from https://www.hult.edu/en/executive education/

Du Brin, A. (2010). Principles of Leadership (6th ed.). Canada: South-Western Cengage-Learning.

El Dahshan, M. E. A., Keshk, L. I., \& Dorgham, L. S. (2018). Talent management and its effect on organization 
performance among nurses at Shebin El-Kom hospitals. International Journal of Nursing, 5(2), 108-123. https://doi.org/10.15640/ijn.v5n2a10

Fornell, C., \& Larcker, D. F. (1981). Evaluating structural equation models with unobservable variables and measurement error. Journal of Marketing Research, 18(1), 39-50. https://doi.org/10.1177/002224378101800104

Gakovic, A., \& Yardley, K. (2007). Global Talent Management at HSBC. Organization Development Journal, 25(2), 201-205.

Gardner, T. M. (2002). In the Trenches at the Talent Wars: Competitive Interaction for Scarce Human Resources. Human Resources Management, 41, 225-237. https://doi.org/10.1002/hrm.10033

Gomez-Mejia, L. R., Balkin, D. B., \& Robert, L. C. (2004). Managing Human Resources (4th ed.). USA: Prentice Hall.

Grobler, P., Wärnich, S., Carrell, M., Elbert, N., \& Hatfield, R. (2002). Human resource management in South Africa (2nd ed.). London: Thomson Learning.

Gruman, J. A., \& Saks, A. M. (2011). Performance management and employee engagement. Human Resource Management Review, 21(2), 123-136. https://doi.org/10.1016/j.hrmr.2010.09.004

Hair, J. F., Sarstedt, M., Ringle, C. M., \& Mena, J. A. (2012). An assessment of the use of partial least squares structural equation modeling in marketing research. Journal of the Academy of Marketing Science, 40(3), 414-433. https://doi.org/10.1007/s11747-011-0261-6

Hayajneh, Y. A., AbuAlRub, R. F., Athamneh, A. Z., \& Almakhzoomy, I. K. (2009). Turnover rate among registerednurses in Jordanian hospitals: An exploratory study. International Journal of Nursing Practice, 15, 303-310. https://doi.org/10.1111/j.1440-172X.2009.01758.x

Heinen, J. S., \& O'Neill, C. (2004). Managing Talent to Maximize Performance. Employment Relations Today, 31(2), 67-82. https://doi.org/10.1002/ert.20018

Higazee, M. Z. A., Rayan, A., \& Khahl, M. (2016). Relationship between Job Stressors and Organizational Support among Jordanian Nurses. American Journal of Nursing Research, 4(3), 51-55。

Hughes, J. C., \& Rog, E. (2008). Talent management: A strategy for improving employee recruitment, retention and engagement within hospitality organizations. International Journal of Contemporary Hospitality Management, 20(7), 743-757. https://doi.org/10.1108/09596110810899086

Iles. (2007). Employees recruitment, retention and engagement within hospitality organizations. International journal of management, $37(2)$.

Kehinde, J. S. (2012). Talent management: effect on organizational performance. Journal of Management Research, 4(2), 181. https://doi.org/10.5296/jmr.v4i2.937

Kennedy, E., \& Daim, T. (2010). A strategy to assist managers in workforce engagement and employee retention in high tech engineering environment. Evaluation and program planning, 4(33), 468-476. https://doi.org/10.1016/j.evalprogplan.2009.12.001

Lawler, E. E. (2003). Reward Practices and Performance Management System Effectiveness. Center for Effective Organizations. https://doi.org/10.1016/j.orgdyn.2003.08.007

Mathias, R., \& Jackson, J. (2006). Human Resources Management (11th ed.). Thomson South-Western.

Meyers, M. C., \& Van Woerkom, M. (2014). The influence of underlying philosophies on talent management: Theory, implications for practice, and research agenda. Journal of World Business, 49(2), 192-203. https://doi.org/10.1016/j.jwb.2013.11.003

Meyers, M. C., Van Woerkom, M., \& Dries, N. (2013). Talent—Innate or acquired? Theoretical considerations and their implications for talent management. Human Resource Management Review, 23(4), 305-321. https://doi.org/10.1016/j.hrmr.2013.05.003

Milky, M. R. (2013). Analysis of Organizational Performance by Using Succession Planning and Talent Management. Master Thesis in Business Administration; Independent University, Bangladesh.

Ministry of Health. (2018). Annual statistical book. Retrieved from https://www.moh.gov.jo/

Mrayyan, M. T. (2005). Nurse job satisfaction and retention: comparing public to private hospitals in Jordan. Journal of Nursing Management, 13(1), 40-50. https://doi.org/10.1111/j.1365-2834.2004.00453.x 
Nafei, W. A. (2016). The Impact of Talent Management on Organizational Performance: Evidence from the Industrial Companies in Egypt. Case Studies Journal, 5(8).

Najm, A. N., \& Manasrah, A. K. (2017). The effect of talent management on organizational performance: applied study in Jordanian banks. Review of Applied Socio- Economic Research, 13(1), 36.

Payambarpour, S. A., \& Hooi, L. W. (2015). The impact of talent management and employee engagement on organisational performance. Int. J. Management Practice, 8(4). https://doi.org/10.1504/IJMP.2015.073483

Phillips, J., \& Connell, A. (2003). Managing Employee Retention: A Strategic Accountability Approach. Burlington: Butterworth-Heinemann. https://doi.org/10.1016/B978-0-7506-7484-3.50005-6

Podsakoff, P. M., MacKenzie, S. B., Lee, J. Y., \& Podsakoff, N. P. (2003). Common method biases in behavioral research: A critical review of the literature and recommended remedies. Journal of Applied Psychology, 88(5), 879-903. https://doi.org/10.1037/0021-9010.88.5.879

Pulakos, E. D. (2009). Performance management: A new approach for driving business results. Malden, MA: Wiley-Blackwell. https://doi.org/10.1002/9781444308747

Richman L., Janet, T., Laurie, L., Shannona, E., \& Robert, T. (2008). The Relationship of Perceived Flexibility, Supportive Work-Life Policies and Use of Formal Flexibility Arrangements and Occasional Flexibility toEmployee Engagement and Expected Retention. Journal of community, work \& Family, 22(2), 183-187. https://doi.org/10.1080/13668800802050350

Rogelberg, S. G., \& Stanton, J. M. (2007). Introduction: Understanding and dealing with organizational survey nonresponse. Organizational Research Methods, 5(2), 122-140. https://doi.org/10.1177/1094428106294693

Sadri, A., Pirouz, H., Sharifi, S., \& Farhadi, M. (2015). Studying the Impact of Talent Management on Performance of Staffs. International Academic Journal of Economics, 2(11), 50-59.

Saif, N. I. (2017). How Transactional and Transformational Leadership Affect Employee Satisfaction in Jordan's Public Hospitals. International Journal of Applied Business and Economic Research, 15(15).

Sareen, P., \& Mishra., S. (2016). A Study of Talent Management and Its Impact on Performance of Organizations. IOSR Journal of Business and Management (IOSR-JBM), 18(12), 66-73.

Shaffer, F. A., Bakhshi, M., To Dutka, J., \& Phillips, J. (2016). Code for ethical international recruitment practices: The CGFNS alliance case study. Human Resources for Health, 14, 31. https://doi.org/10.1186/s12960-016-0127-6

Smith, P. C., \& Goddard, M. (2002). Performance management and operational research: A marriage made in heaven? Journal of the Operational Research Society, 53, 247-255. https://doi.org/10.1057/palgrave.jors.2601279

Stahl, G., Bjorkman, I., Farndale, E., Morris, S., Paauwe, J., \& Stiles, P. et al. (2007). Global talent management: How leading multinationals build and sustain their talent pipeline. Faculty \& Research Working Paper, INSEAD Working Paper Series.

Stevens, H. P. (2008). Total Quality Management Now Applies to Managing Talent. The Journal for Quality \&Participation.

Vaiman, V., \& Vance, C. M. (2008). Smart Talent Management. Cheltenham: Edward Elgar Publishing. https://doi.org/10.4337/9781848442986

Vitez, O. (2012). Performance management components. Retrieved from http://www.ehow.com/list_6080442performance-management-system components.Html

Ying, Z. Y. (2013). The impact of a performance management system on employee performance.

Zhang, Y. (2012). The impact of performance management system on employee performance-Analysis with WERS 2004 (Master's thesis, University of Twente).

\section{Copyrights}

Copyright for this article is retained by the author(s), with first publication rights granted to the journal.

This is an open-access article distributed under the terms and conditions of the Creative Commons Attribution license (http://creativecommons.org/licenses/by/4.0/). 